The International Conference : Cities’ Identity Through Architecture and Arts (CITAA)

\title{
The spatial identity of historic Cairo. Part one: typology, geometry, and geographic distribution
}

\author{
DOI: $10.21625 /$ archive.v1i1.131 \\ Sadek A. S. Saad ${ }^{1}$ \\ ${ }^{1}$ Prof. of architectural and urban design, dept. of architectural engineering, college of engineering, Shoubra, \\ Benha University
}

\section{Keywords}

City identity, place identity, urban form, urban spaces, historic Cairo

\begin{abstract}
It is fundamental to maintain the local places' identity, chartacter and trajectory of evolution in order to create a sustainable process of urbanization.

This study introduces a quantitative inventory of urban spaces in Cairo, in the early 19th century, extracted from historic maps and indexes. Urban spaces are classified in terms of geometric typology (linear and central), geometric regularity of their footprints, sizes and geographical distribution.

The extracted information highlighted the quantitative domination of linear spaces and of irregularity in space footprint. It also showed a noticeable insignificant value of central spaces. However, the insignificant value of central spaces presented spatial identity of power demonstration in historic Cairo; irregularity and linearity presented sociocultural and economic identities.
\end{abstract}

\section{Introduction}

Oktay (2001) emphasized the importance of creating a sustainable urbanization process, and one way to achieve this is through maintaining the unique identity, character, and evolution of local places. Identity is an important issue 'because it involves the self-identity has consequences for cognition, affect, and behaviour' (Devine-Wright \& Clayton, 2010, p. 267). Place identity could exist at different scales, like in a home, a city, or a country. Moreover, it could include other categories, like outdoor spaces (Bonaiuto \& Alves 2012). Place identity could also be seen as a component of personal and social identity. Thus, through interaction with places, people describe themselves in terms of the belonging to a specific place (Hernandez et al. 2007). Empirical studies showed a 'significant and positive correlation between place identity and neighborhood satisfaction. ...[Such] correlation was also found between place identity and perception of the quality of one's own neighborhood' (Bernardo \& Palma-Oliveira 2016, p. 247). It is proven that 'autobiographical memory in relation to place, ... facilitates attachment, or perceptions of an environment as a "place of mine", rather than simply a place recognized through general knowledge’ (Ratcliffe \& Korpela 2016, p. 120).

\section{Urban spaces and geometry:}

Moughtin \& Mertens (2006) considered urban spaces and buildings to be the cardinal elements creating the city identity. While 'urban open space is a term used to define regions of "vacant lots," "natural landscapes" and "public green spaces” in cities' (Kim 2011, p. 2), urban spaces require physical elements to be defined (Krier 2005) and aesthetic values to be recognized (Sitte 1909). Space is a three-dimensional element that should be described in terms of width, length, and height. In spite of the argument that space is 'not just the "physical structure"' (Fuchs 2011, p. 25), the fact that physical structure is its primary generating parameter remains valid, for the quality of 
the space-vertical-surrounding elements and its footprint are the 'defining physical structure' of creating an urban space (Städtebauliches Institut, 1972). Meanwhile, the mere physical existence of a central space, for example, does not guarantee its use as a public square. Since there is no guarantee 'that the microclimatic conditions would be favourableso, the people would be comfortable interacting with it' (Giddings et al. 2011, p. 205) and no guarantee it will be considered as an effective urban space in terms of sociocultural activities and aesthetics conditions. Sitte (1909). considered the minimum dimension of a 'Platz' to roughly be equal to the height of its vertical defining elements, and while he presented the largest public place in ancient cities to measure: 58X143m, Moughtin \& Mertens (2006, p. 101) considered the upper limit of a public place dimension to be $135 \mathrm{~m}$. Furthermore, the list of city squares (around the world) by size published by Wikipedia (n.d.), presented the Tallinn city square, Estonia to be the smallest and measuring: 75X75m.

Urban spaces are classified according to different perspectives, such as accessibility (Nardo 2009, p. 24), form and function (Lynch 1972), geometry (Saad 1994), contextual location (Alhusban 2012) and typology (Krier 2005). Whereas Kirjakka (2010) remarked that open places could be categorized according to their function, Zuker (1959) considered function-based categorization as a seldom relevant in morphological research because it does not automatically produce a spatial form. Sitte's (1909) classification of urban spaces is categorized into two types, street, and square, greatly inspired Krier (2005), Moughtin \& Mertens (2006). While Nardo (2009) and Alhusban (2012), for example, neglected street space in their classifications, Soto (2012, p. 10) considered street space to embody 'movement, access, and public life, for liveable streets enhance the quality of life'. Meanwhile, Krier (2005) suggested that the primary difference between each type of urban space is basically geometric and the common distinctive factor in Zuker (1959) classification could also be regarded as a geometric one too. Whyte (1980) empirically proved that geometry is a major element in determining space quality, and Key (2012, p. 8) argued that space physical delimitations, footprint, and type: 'linear or central -all these factors tell us what kind of activities these spaces afford'. According the premise that 'specific forms of built environment afford specific forms of sensory experience’ (Degen \& Rose 2012, p. 3283), Faye \& Le Fur (2012, pp. 3086-3090) discussed a set of variables generating the symbolic dimensions of a square space, which include its size and form. Such arguments imply that activity can be a final product of space geometry. As for the European urbanization, 'squares are the most representative of the values of the societies that created them' (Giddings et al. 2011, p. 203), Saad (2000b) proved that local non-physical determinants in historic Cairo, have driven the Friday mosque's inner courtyard to play a role similar to that of European Public Square by offering opportunities for sociocultural activities to take place. The notion that the square shape is inherently static and non-directional (Wagner 1981; Ching 2007) can be seen as a motivation for considering public squares more suitable for static activities and streets more suitable for dynamic ones (McCulskey 1992; Frederick 2007). Meanwhile, El-Husseiny’s observational study on historic Cairo streets proved that they accommodate both dynamic and static activities. Although the mosques' courts 'are not the only static spaces in the urban fabric, they would be categorized as the top of spacious stasis in the organism. Because of their uniform squaring shape, wall stones, and tight enclosure. Silence, birds’ voices and planting may lead stasis to perfection’ (El-Husseiny \& El-Husseiny 2012, p. 689). Different terms are interchangeably used to describe streets and squares according to aesthetic treatments and cultural values. Accordingly, to avoid any confusion in using different descriptions and simultaneously generalize the terms used, this study adopts a geometric approach. The length-to-width proportion of a 'street' should exceed 3:1 (Saad 1994), and because of the geometric proportions of its footprint, 'street' will be considered as a 'linear urban space' (hereinafter, LS). On the other hand, footprints of urban spaces varying between 1:1 and 1:2 (Städtebauliches Institut, 1972) will be classified as 'central urban spaces' (i.e. the Public Square will be considered geometrically as ‘central spaces’ (hereinafter, CS)).

\section{Inventory method and process:}

Ding \& Ziyu (2010) suggested moving the researchers’ knowledge toward the operational level by quantitatively analysing urban forms. Moreover, Krier (2005) geometric classification was criticized by Murthy (2010, p. 5) as being 'oriented towards an experiential account rather than a descriptive one'. Hence this study produces a descriptive and quantitative inventory of urban spaces in terms of space typology, geometric quality, size and geographical distribution, such inventory should help in identifying some aspects of the spatial identity of historic Cairo.

The author argues that urban spaces in contemporary Cairo have lost their genuin local identity. Koch \& Latham (2013, p. 13) discussed the notion presented by Zukin (2010), considering historic spaces to be 'wild' compared with the 'tamed' contemporary spaces. They concluded that this may be due to the 'natural order [created by the] collective negotiation of multiple claims'. Fuchs (2011, p. 25) questions how 'people construct their urban environment, both cognitively and physically', which can be answered by studying historic unplanned cities, since they should contain more 'wild' than 'tamed' spaces. In order to study 'wild' spaces rather than 'tamed', this study targeted the historic urban fabric. Cairo before the beginning of the 19th century is considered to be an informal 
(unplanned) city (Raymond 2001). The time frame for this research was chosen primarily because of the availability of cartographic material- around the beginning of the 19th century Cairo (henceforth: historic Cairo).

Historic Cairo could be considered in terms of two urban spheres: public and private. The first of which, containing roads network (in the total length of 36,620 m), is divided into the following: the city centre major arterial road (El-Aazam Street), three other major arterial roads (1, 2 and 3) and the network of minor arterial roads (see Fig. 1). Cairo city centre occupied the central major arterial road; however, the sub-centres created several major and minor arterial roads (Raymond 2002). The private sphere, on the other hand, represented the residential areas of the city, which took the form of closed introverted urban entities (Saad \& Eysa 2004). The roads within the residential areas produced a network comprising $128,170 \mathrm{~m}$. It should be noted that, in this study, the distinction between public and private emphasizes territorialities, rather than ownership.

This study adopted the following steps during the inventory process:

1. Every urban space on the Cairo map, 1:5000 (known and henceforth: the 'Napoleon map') (Egyptian Authority for Surveying 1910), was isolated and identified in terms of its typology: linear or central (see Fig. 2 presents examples for Linear and central spaces in historic Cairo).

2. Isolated urban spaces were categorized according to the research objectives and their geographical distribution within the city public and private spheres.

3. Urban spaces in each group and subgroup were counted to create a quantitative inventory.

\section{Results and discussion:}

The inventory of the Napoleon map (Egyptian Authority for Surveying 1910) produced a total of 3922 urban spaces. In term of space typology, 3377 are labled as linear, and 545 are labled as central spaces. LSs accounted for $86 \%$ of the total urban spaces in historic Cairo; the percentage increased to $91 \%$ within the private sphere and dropped to $74 \%$ within the public sphere. Where $28 \%$ (out of 545) CSs exist in the public sphere, $72 \%$ exist in the private sphere. Such results should be seen in the light of the total length of each sphere road network (36,620 m and 128,170 respectively). In terms of the spatial quality, $92 \%$ of all urban spaces demonstrated geometric irregularity of footprints on the global (Macro) level. Where 94\% of LSs and 91\% of CSs presented irregularity, on the global level, this percentage drooped to $81 \%$ and $88 \%$ within the public sphere and incresed to $96 \%$ and 93\% for LSs and CSs respectively within the private sphere.

Concerning sizes and distribution, the biggest open area in historic Cairo is located in the city citadel area, an open area coded in this study as 7/1/1, measuring approximately $81,200 \mathrm{~m} 2$ (see Fig. 3). This area is the most regular urban open area in historic Cairo, and its regularity degree and size successfully competes against Friday mosques' inner courtyards. Although this inventory proved the quantitative domination of geometric irregularity among urban spaces in historic Cairo, open area 7/1/1 is in total contrast with such phenomenon. Furthermore, open area $7 / 1 / 1$ presents a very low degree of enclosur which hinders it from being physically considered as an urban space. CSs in historic Cairo were classified into four main size groups: very small ( $\leq 39 \mathrm{~m} 2)$, small ( 40 - $300 \mathrm{~m} 2)$, medium ( $400-2000 \mathrm{~m} 2)$ and big-size $(\geq 4000 \mathrm{~m} 2)$ spaces. The investigation of the Napoleon map provided the following findings: $77.5 \%$ out of 545 were found to be very small, $19.5 \%$ small, 11 medium spaces, and five big CSs. Both medium and big spaces presented 3\% only of all CSs in historic Cairo (see Fig. 4 for an example of a relative scale comparison). The smallest CS in historic Cairo measured approximately 15m2, CS 9/1/1 represents the biggest footprint of a real CS in term of its physical structure, measuring around 22,400 $\mathrm{m} 2$ and located between the biggest two monuments in Cairo: the Sultan Hassan mosque and Cairo citadel (see Fig. 3). Spatial cluster 8/1/1 presented four big CSs with areas varying between 4,400 $\mathrm{m} 2$ and 7,475m2 (the biggest space dimension of approximately 115X65m), and three medium CSs measuring between $500 \mathrm{~m} 2$ and $1,125 \mathrm{~m} 2$.]

Furthermore, the investigation revealed a CS-size-function-geographic relationship: $94.5 \%$ of very small CSs existed within the city private sphere (in a scattered form), and $86.5 \%$ of small CSs were distributed within the public sphere, especially major commercial roads (in linear form). The city major arterial roads occupted the first rank in the density level (density in this context reflects the number of CSs divided by the road length) of small CSs in linear distribution and city-citadel-area, six out of eleven medium CSs and all big CSs (in a centralized form). The citadel area presented the biggest urban open area (7/1/1), the biggest CS (9/1/1) and the biggest spatial cluster (8/1/1)).

From all central spaces found in historic Cairo only 16 CSs (3\%) presenting potential identity of Public Squares pertaining the size, geometry, and geographic distribution. Such potentiality must be further investigated since their mere physical existence does not guarantee their use (Francis et al. 2012, p. 402). Small and very small CSs on the other hand, is not appropriate in terms of size to function as Public Squares (since their dimension is too 
small to afford sociocultural activities). Meanwhile, the spatial identity of historic Cairo could be discussed (in the light of this study objectives) in two major aspects: spatial unity/diversity and visual clarity/orientation.

\section{Unity and diversity of urban spaces in historic Cairo:}

This study results reinforced the argument that historic Cairo followed a 'Darwinist' rule of evolution to create such typological and spatial identity, through which certain types of urban spaces prevailed, and others became recessive. Generally, diversity might reflect one of two possible meanings; it either reflects urban disorder or it reflects intention. If randomness is the case, the quantitative inventory must imply randomness. In fact, it implies domination of certain spatial characters and recession of others. While dominant spatial elements create visual unity, recessive elements create the visual diversity. Such diversity is presented in its strongest form in the citadel area. Hakim (2001) argued that there are two types of rules-operating simultaneously-contributing 'to the phenomenon of the diversity of settlements within specific sub-regions of the Islamic world. Yet, it is unified by the general concepts and attitudes that all regions shared'.For a deeper understanding of the impact of such diversity in urban spaces on the spatial identity of historic Cairo, the issues of visual clarity and orientation should be addressed.

Visual clarity and orientation in historic Cairo: Geometric irregularity was (and still is) a ground for many misconception and historic Cairo is no exception. Cruceru (2011, p. 96) argued that the spatial configuration is regarded as 'providing clarity of the spatial layout, orientation, and accessibility'; thus, simple shapes of space footprint and geometric regularity create a clear visual orientation which promotes accessibility since it can decrease 'negative feelings of stress and anxiety' (Alhusban 2012, p. 39). Though providing visual clarity or confusion in the urban orientation are two symbolic meanings, we should consider emphasizing on clarity not only as culturally understandable but also as insufficient for the design parameter.

The public sphere in historic Cairo demonstrated a clearer visual orientation due to the domination of LS, higher degree of geometric regularity and higher density of CSs. Furthermore, the city centre major arterial road, as the city civic centre, presented the highest degree of geometric regularity and the highest density in CSs. Thus in the public sphere, the city presented a clearest degree of visual orientation to promote accessibility. On the other hand, historic Cairo's private sphere, in which social life is highly valued, strangers are not welcomed by the domination of irregular LSs. The highest degree of geometric irregularity and the low density in CSs resulted in creating a visual confusion and disorientation to complicate its accessibility. Such visual confusion led to an intended increase in stress or anxiety among strangers accessing the residential private sphere.

But does such diversity in visual clarity, orientation and spatial quality between both Cairo public and private spheres contributed to placing identities by strengthening the social, cultural and/or the political symbolic quality of spaces in historic Cairo?

\section{Environmental and place identities in historic Cairo:}

The city is a powerful source of expressive symbols and signs, 'People know their location in space and differentiate themselves from others through a... reading of the elements that make up places' (Nojima 2000, p. 2/59). Different scales of governance networks create a diversity of identities such as 'environmental identity' and 'place identity' (Pflieger \& Rozenblat, 2010, p. 2725). However, since the two types of rule systems presented by Hakim (2001, p. 89) are 'proscriptive, [they have] the liberty to generate solutions to specific local problems in response to the site and the conditions around it'.

The clear diversity in space typology and spatial quality -between the public and private spheres- contribute to creating different identities for each sphere. On the global level, a certain degree of visual unity is established through the general impression of geometric irregularity and the domination of LSs over CSs and the intention for adapting small and very small CSs for creating an urban intimacy. The citadel area presents a clear spatial contrast to its public sphere context with its vast open space, the concentration of medium and big CSs and their spatial quality. On the global level, three different spatial identities could be crystalized. The first local identity is presented within the public sphere. The public sphere demonstrates a tendency for creating more regular spaces and introducing small CSs along its major arterial roads. The citadel area presents the second spatial local identity by adapting the most regular spaces, the biggest regular open area in the city and the concentration of most of the medium and all big CSs in the city. Such spatial form created a very strong visual celebrative and/or monumental identity. Al-Maqrizi (1441) and Raymond (2002) gave historical evidence that the citadel area (during the Mamluk (1250-1517) and Ottoman (1517-1798) eras) exhibited a residential area for the ruling military-political elites and their related urban services. Thus, this area was strongly influenced by the political and military powers resulting in creating regular and monumental spaces (Kostof 1991, p. 230). Such concentration of CSs could be comprehended within the military-elites power demonstration of 'governing network level' (Pflieger \& Rozenblat, 2010, p. 2725). The highest degree of geometric irregularity, the quantitative domination of LSs, and the existence of very small central spaces presented the third local identity for historic Cairo private sphere. The high degree of 
visual disorientation in the private sphere, which is produced from its spatial characters, may be regarded as an added value to its place identity, associated with the concept of affordance inviting or demanding self-identification with the place. Where 'individuals who strongly identify themselves with a particular place may take action on behalf of that place, either to try to remedy problems that already exist there or to prevent forms of negatively interpreted change from occurring' (Devine-Wright \& Clayton, 2010, p. 269). Thus, due to the high social control practised by its residents, it is unsurprising that residential areas in historic Cairo enjoyed a high degree of safety and security (Raymond 2002).

Conclusion: Mills (2012, p. 379) considered the examination of space to be 'broader than an effort to map the physical landscape'. This inventory has presented neither random nor homogeneous distributions for its findings. While a random distribution for space typology and/or quality might indicate randomness in their creation, homogenous distribution can reflect the non-existence of any favourite spatial elements and quality in historic Cairo. The study quantitative results showed a clear bulking in favour of certain spatial elements and quality as well as very small volumetric existence for others. The quantitative domination of LSs (86\%-91\%) and the domination of irregularity in the geometric form (90\%-96\%) have created clear bulking existences.

The unity of historic Cairo's spatial identity could be described within the following parameters: the quantitative domination of LSs, the geometric irregularity of space footprints, and the quantitative recession in CSs. Its place identity was presented by its spatial diversity in terms of footprint shapes and geometric irregularity. In terms of sizes, the medium and big urban spaces, as well as vast open spaces, demonstrated a very recessive phenomenon which could draw to a political and military visual celebrity impact of the elite classes.

Diversity is produced by creating three different place identities for the public and private spheres as well as the citadel area, which can be seen as a clear and conscious intension.

On the local levels, the public sphere showed following spatial characterises: the highest degree of quantitative domination of LSs, the average level of geometric irregularity in space footprint and a strong recession in CSs. The city centre major arterial road (El-Aazam Street) revealed the quantitative domination of LSs, a higher density in CSs and the highest degree of geometric regularity in space footprint (relatively to the public sphere itself). The public sphere revealed the highest degree of accessibility and the clearest visual orientation. On the other hand, the private sphere identity can be characterized by a very high quantitative domination of LSs (91\%), very clear domination of geometric irregularity (96\%) and a very low density in CSs among which very small CSs quantitatively prevailed. The private sphere revealed the highest degree of visual disorientation or confusion.

This inventory proved the existence of central spaces in historic Cairo, in terms of geometry and physical structure, but their marginal existence in the city proves their insignificant value in the daily life of the city residents. Furthermore, the facts that CSs presented a very recessive phenomenon among which very small CSs were dominant, and $72 \%$ of which existed in the private sphere of historic Cairo, leave a very marginal volume of CSs (3\%) to be potentially considered as Public Squares in terms of geometry. With accordance to the aformentioned observation, public Squares cannot be recommended to be adapted as a typical spatial identity for Cairo. Further studies should be conducted in order to check the real urban value of those central spaces. Their geometric shape and size, their visual and aesthetic values, and their urban functions should be investigated in order to identify them as public squares or traffic nodes. 


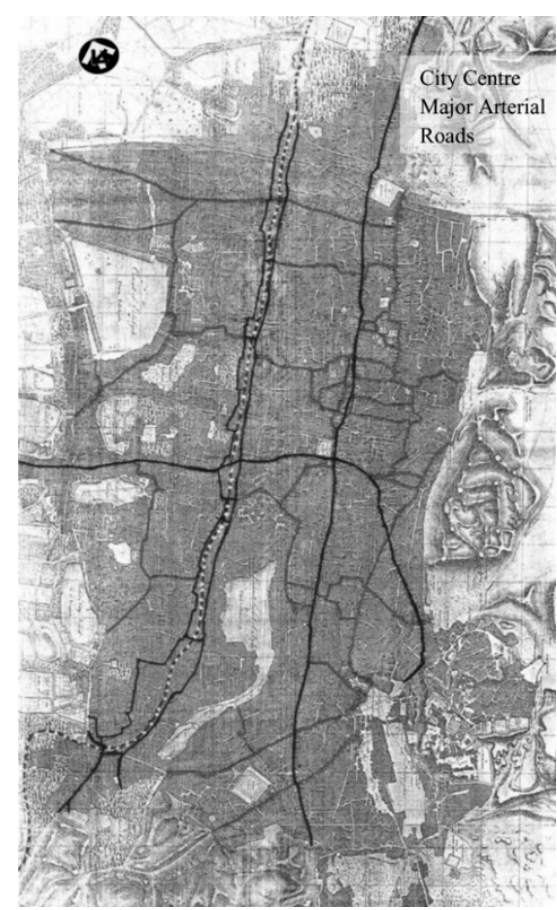

Fig. 1. The City major arterial roads, on the Napoleon map, the author.

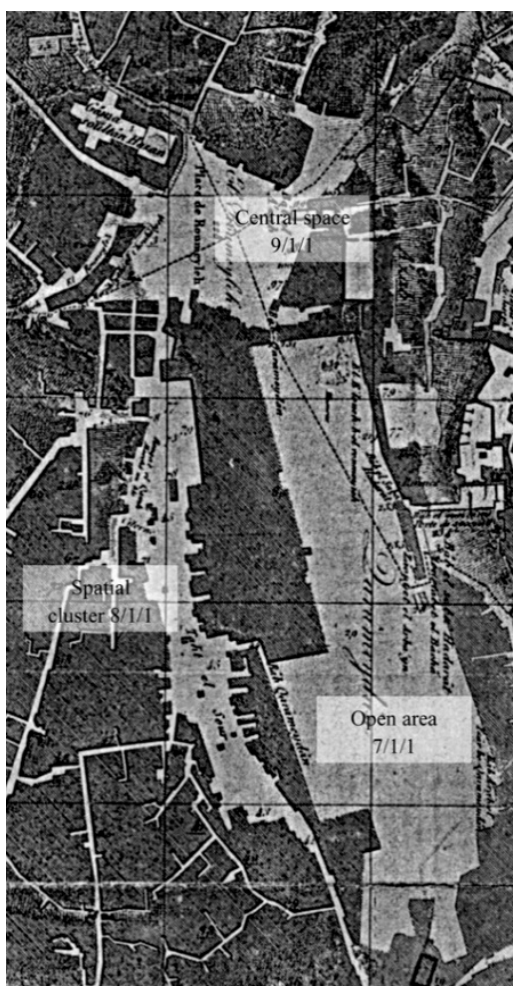

Fig.3. Cairo Citadel area, a concentration of central urban spaces', the Napoleon map
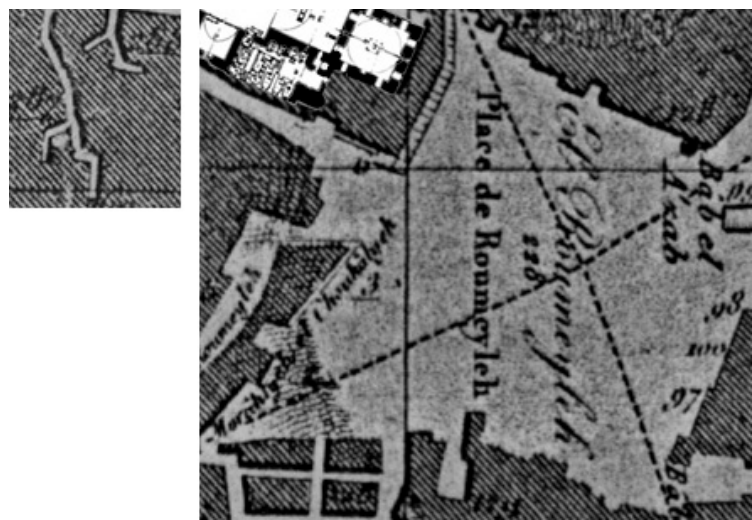

Fig. 2. Typology of urban spaces in historic Cairo: Linear and central spaces, examples

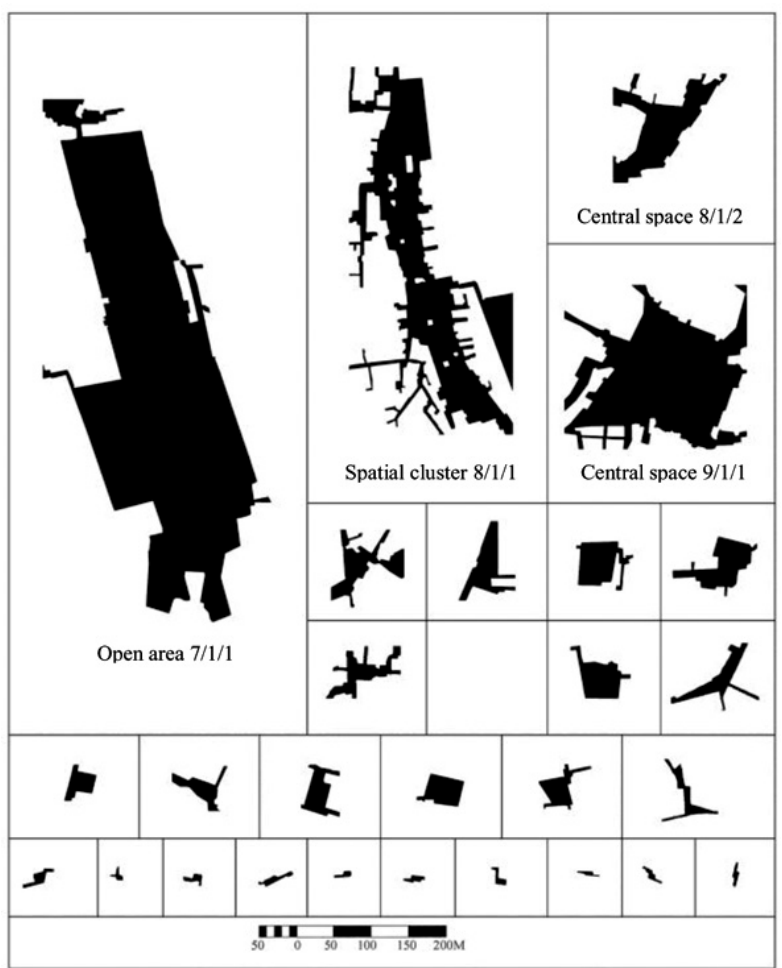

Fig. 4. A relative scale comparison between different sizes of central urban spaces; big, medium, small, and very smal spaces, and the biggest open area in historic Cairo coded as $7 / 1 / 1$

\section{References:}

1. Alhusban, S.A., 2012. The architectural design of plazas, social capital, and cultural hybridity in urban neighborhoods: Defining a multidimensional network model for public health promotion. Ph.D. Washington State University, United States -- Washington.

2. Bernardo, F. and Palma-Oliveira, J.-M., 2016. Urban neighbourhoods and intergroup relations: The importance of place identity. Journal of Environmental Psychology, 45, 239-251. 
3. Bonaiuto, M. and Alves, S., 2012. Residential places and neighbourhoods: toward healthy life, social integration, and reputable residence. In S. Clayton (Ed.), The Oxford Handbook of environmental and Conservation psychology. New York: Oxford University Press, 221247.

4. Ching, F., 2007. Architecture; Form - Space and Order. New Jersey: John Wiley and Sons Inc.

5. Cruceru, A., 2011. Urban form, transit space, and the public realm. Master. University of Guelph, Canada.

6. Degen, M. and Rose, G., 2012. The Sensory Experiencing of Urban Design: The Role of Walking and Perceptual Memory. Urban Studies, 49 (15), 3271-3287.

7. Devine-Wright, P. and Clayton, S., 2010. Introduction to the special issue: Place, identity and environmental behaviour. Journal of Environmental Psychology, 30 (3), 267-270.

8. Ding, W. and Ziyu, T., 2010. A Methods Approach on Study Street Spatial Type. Presented at the 17th International Seminar on Urban Form, Hamburg.

9. Egyptian Authority for Surveying, 1910. Cairo Map, Known as; the 'Napoleon Map'.

10. El-Husseiny, A.M.E. and El-Husseiny, A.A.E., 2012. Integration of Static and Dynamic Spaces in Historic Cairo: A Community Spirit that May Vanish. Procedia - Social and Behavioral Sciences, 68, 687-699.

11. Faye, B. and Le Fur, É., 2012. Square, Plaza, Piazza, Place: What Do We Know about these Targets of Urban Regeneration Programmes? Urban Studies, 49 (14), 3081-3099.

12. Francis, J., Giles-Corti, B., Wood, L., and Knuiman, M., 2012. Creating sense of community: The role of public space. Journal of Environmental Psychology, 32 (4), 401-409.

13. Frederick, M., 2007. 101 Things I Learned in Architecture School. Massachusetts: MIT Press.

14. Fuchs, R.G., 2011. Public Spaces and Private Lives in Paris: Introduction. Journal of Urban History, 37 (1), $24-27$.

15. Giddings, B., Charlton, J., and Horne, M., 2011. Public squares in European city centres. Urban Design International, 16 (3), $202-212$.

16. Hakim, B.S., 2001. Reviving the Rule System: An approach for revitalizing traditional towns in Maghrib. Cities, 18 (2), 87-92.

17. Hernandez, B., Hidalgo, M., Salazar-Laplace, M., and Hess, S., 2007. Place attachment and place identity in natives and non-natives. Journal of Environmental Psychology, 27, 310-319.

18. Key, S., 2012. A Computable Language of Architecture Towards building descriptive models of spatial qualities. Ph.D. Carnegie Mellon University, United States -- Pennsylvania.

19. Kim, W.K., 2011. Understanding Open Spaces in an Arid City. Ph.D. Arizona State University, United States -- Arizona.

20. Kirjakka, M., 2010. Urban Open Spaces in Historic Finish Cities. Presented at the 17th. International Seminar on Urban Form, Hamburg.

21. Koch, R. and Latham, A., 2013. On the Hard Work of Domesticating a Public Space. Urban Studies, 50 (1), 6-21.

22. Kostof, S., 1991. The City Shaped: Urban Patterns and Meanings through History. London: Thames and Hudson.

23. Krier, R., 2005. Urban Space. Solingen: Umbau-Verlag, Solingen.

24. Lynch, K., 1972. The Openness of Open Space. In: Gyorgy, Kepes (ed.) Arts of the Environment. New York: George Brazille.

25. Al-Maqrizi, T. al-D., 1441. El-mawa'iz wa'l I’tibar fi Dhikr El-khitat wa’ L-athar [Topographic and historical Description of Egypt]. Cairo: Bulaq Press.

26. McCulskey, J., 1992. Road Form and Townscape. London: Architectural Press.

27. Mills, A., 2012. Urban Space and Social Transformation in the Middle East. Journal of Urban History, 38 (2), $379-384$.

28. Moughtin, C. and Mertens, M., 2006. Urban Design: Streets and Square. 3rd. ed. London: Architectural Press.

29. Murthy, M., 2010. Contemporary Interpretation on Traditional Urban Space- A Critical Analysis of Rob Krier as Postmodern Phenomenon. Presented at the 17th. International Seminar on Urban Form, Hamburg.

30. Nardo, T., 2009. Architecture of Urban Spaces: A Proposal for Quality Urban Design. Master. Dalhousie, Halifax.

31. Nojima, V.L., 2000. Urban Environmental Language and Spatial Organization. Proceedings of the Human Factors and Ergonomics Society Annual Meeting, 44 (8), 56-59.

32. Oktay, D., 2001. The quest for urban identity in the changing context of the city: Northern Cyprus. Cities, 19 (4), $261-271$.

33. Pflieger, G. and Rozenblat, C., 2010. Introduction. Urban Networks and Network Theory: The City as the Connector of Multiple Networks. Urban Studies, 47 (13), 2723-2735.

34. Ratcliffe, E. and Korpela, K.M., 2016. Memory and place attachment as predictors of imagined restorative perceptions of favourite places. Journal of Environmental Psychology, 48, 120-130.

35. Raymond, A., 2001. Cairo: City of History. Cairo: The American University in Cairo Press.

36. Raymond, A., 2002. Arab Cities in the Ottoman Period: Cairo, Syria and Maghreb. London: Ashgate Publishing Limited.

37. Saad, S., 1994. Die Visuellen und Ästhetischen Faktoren, die die Gestaltung der Städtischen Räume beeinflussen, am Beispiel von Kairo [The Visual and Aesthetic Factors affecting Urban Spaces in Cairo]. PhD. Technical University, Vienna.

38. Saad, S., 2000. Public Squares in Historic Cairo. A Morphological Approach. Presented at the International Engineering Conference, Mansoura, Egypt: University of El-Mansoura, 387-401.

39. Saad, S. and Eysa, H., 2004. Close-end Streets and Urban Territorialities in Historical Cairo. A Quantitative Evaluation. Assiut University, 32 (4), 1859-1870.

40. Sitte, C., 1909. Der Städtebau nach seinen künstlerischen Grundsätzen. Vienna: Grässer.

41. Soto, M.A., 2012. Pedestrian Areas in Los Angeles: Influence of design features and market area on pedestrian activity. A case study of three commercial strips. Master. University of California, Los Angeles, United States -- California.

42. Städtebauliches Institut, 1972. Ziele der Stadtgestaltung. Stuttgart: Stuttgart University, Technical No. 2.

43. Wagner, F., 1981. Grundlagen der Gestaltung. Stuttgart: Kohlhammer Verl.

44. Whyte, W., 1980. The Social Life of Small Urban spaces. Washington: The Conservation Foundation.

45. Zuker, P., 1959. Town and Square. New York: Columbia University Press.

46. Zukin, S., 2010. Naked City, the Death and Life of Authentic Urban Place. Oxford: Oxford University Press. 